\title{
The Relation Between The Workload Of Nurse Executor And Work Stress In The Hospital Ward Of RSUD Sleman
}

\author{
Pandu Wicaksono \& Nur Yeti Syarifah
}

\begin{abstract}
Background: Job stress on nurses can be caused by various factors, one of which is the workload of nurses. Nurse is a benchmark that determines the quality of hospital health services, especially in inpatient wards.

Objective: To find out the relation between the workload of nurse executor and work stress in the hospital ward of RSUD Sleman.

Method: The type of the research is an analytic descriptive with a cross sectional approach. Sampling technique: accidental sampling. Population 91 people. Data were taken using questionnaires.

Results: The results showed that nurse workload in the hospital ward of Sleman Hospital was in the light category, 40 people $(59,7 \%)$ and nurse job stress were mostly in high category work stress as many as 39 people $(58,2 \%)$.

Conclusion: There is a significant relationship between workload of nurse executor with work stress in the hospital ward of RSUD Sleman.
\end{abstract}

Keywords: Workload, nurse work stress

\section{Pendahuluan}

Rumah sakit sebagai pusat pelayanan kesehatan juga harus dapat dapat memberikan kualitas pelayanan yang baik bagi pasiennya. Peningkatan kualitas pelayanan rumah sakit harus disertai dengan peningkatan pelayanan keperawatan, salah satunya melalui upaya peningkatan kinerja perawat. Pelayanan terhadap pasien membutuhkan pelayanan yang profesional. Dalam hal ini, peranan perawat dalam rumah sakit sangat penting. Perawat adalah tolak ukur yang menentukan kualitas pelayanan kesehatan rumah sakit ${ }^{1}$.

\section{Afiliasi Penulis}

Prodi IImu Keperawatan STIKES Wira Husada Yogyakarta

\section{Korespondensi kepada}

N.Y. Syarifah

nuryeti_syarifah@yahoo.co.id
Beban kerja merupakan keadaan dimana seseorang melakukan suatu usaha yang harus dikeluarkan oleh seseorang untuk memenuhi permintaan dan untuk menyelesaikan banyaknya pekerjaan yang diberikan yang harus diselesaikan dalam batas waktu tertentu².

Faktor yang mempengaruhi beban kerja perawat adalah kondisi pasien yang selalu berubah, jumlah rata-rata jam perawatan yang di butuhkan untuk memberikan pelayanan langsung pada pasien melebihi dari kemampuan seseorang, keinginan untuk berprestasi kerja, tuntutan pekerjaan tinggi serta dokumentasi asuhan keperawatan ${ }^{3}$.

Stres kerja merupakan perasaan atau emosi yang tertekan, tidak senang terhadap sesuatu keadaan pekerjaan atau keadaan di dalam lingkungan kerja yang dihadapi oleh mental, fisik, emosional, dan spiritual yang pada suatu saat dapat mempengaruhi kesehatan fisik ${ }^{4}$.

Rumah Sakit Umum Daerah Sleman (RSUD Sleman) adalah rumah sakit pemerintah tipe B 
Tabel 1 | Distribusi frekuensi responden menurut jenis kelamin No. Jenis Kelamin Frekuensi (n) Persentase (\%)

\begin{tabular}{cccc}
\hline 1 & Perempuan & 54 & 80,6 \\
2 & Laki-laki & 13 & 19,4 \\
\hline & Total & 67 & 100,0
\end{tabular}

Sumber: Data Primer

Tabel 2 | Distribusi frekuensi responden menurut pendidikan No. Pendidikan Frekuensi (n) Persentase (\%)

\begin{tabular}{cccc}
\hline 1 & SPK & 5 & 7,5 \\
2 & D3 & 57 & 85,1 \\
3 & D4 & 3 & 4,5 \\
4 & S1 & 2 & 3,0 \\
\hline & Total & 67 & 100,0
\end{tabular}

Sumber: Data Primer

Tabel 3 | Distribusi frekuensi responden menurut umur

\begin{tabular}{|c|c|c|c|}
\hline No. & Umur & Frekuensi (n) & Persentase (\%) \\
\hline 1 & SPK & 5 & 7,5 \\
\hline 2 & D3 & 57 & 85,1 \\
\hline 3 & D4 & 3 & 4,5 \\
\hline 4 & S1 & 2 & 3,0 \\
\hline \multicolumn{2}{|c|}{ Total } & 67 & 100,0 \\
\hline
\end{tabular}

Sumber: Data Primer

Tabel 4 | Distribusi frekuensi responden menurut masa kerja

\begin{tabular}{rccc} 
No. & Masa Kerja & Frekuensi (n) & Persentase (\%) \\
\hline 1 & $<3$ tahun & 21 & 31,3 \\
2 & $>3$ tahun & 46 & 68,7 \\
\hline & Total & 67 & 100,0
\end{tabular}

Sumber: Data Primer

dengan kapasitas 284 tempat tidur dengan perawat pelaksana berjumlah 91 orang di bangsal rawat inap. Dengan rata-rata 12 perawat pelaksana di setiap bangsal yang dibagi menjadi 3 shift yaitu pagi, siang, dan malam dengan rata-rata setiap bangsal rawat inap ada 14 pasien maka setiap perawat pelaksana merawat 4 pasien setiap shiftnya. Berdasarkan rata-rata hasil data per bulan didapatkan hasil bahwa Bed Occupation Rate (BOR) atau tingkat pemanfaatan tempat tidur sebesar $66,50 \%$ dengan standar nasional $75-85 \%$, Average Length of Stay (ALOS) atau rata-rata lama pasien dirawat selama 5 hari dengan standar nasional 3-9 hari, Turn Over Interval (TOI) atau rata-rata lama tempat tidur kosong selama 2 hari dengan standar nasional 1-3 hari, dan Bed Turn Over (BTO) atau frekuensi pemakaian tempat tidur dengan periode tertentu sebesar 4,49 kali, dan dengan rata-rata jumlah pasien rawat inap sebanyak 1,031 pasien/bulan. Berdasarkan hasil wawancara kepada kepala keperawatan mengatakan bahwa tingkat beban kerja pada setiap bangsal berbeda dan perawat tentu mempunyai beban kerja dalam setiap tindakan yang dilakukan, untuk jangka waktu tertentu bebannya ringan dan pada saat lain bisa terjadi berlebihan atau berat yang bisa mengakibatkan beberapa diantaranya mengalami stres kerja. Berdasarkan latar belakang yang telah diuraikan, maka peneliti tertarik untuk meneliti tentang hubungan beban kerja perawat pelaksana dengan stres kerja.

\section{Metode}

Jenis penelitian ini termasuk penelitian kuantitatif menggunakan deskriptif analitik korelasional dengan pendekatan cross sectional yaitu antara variabel independent dan dependent diukur pada waktu dan tempat yang bersamaan ${ }^{5}$. Teknik sampel menggunakan teknik Accidental Sampling. Peneliti melakukan pengumpulan data dengan cara membagikan kuesioner kepada responden, analisis data menggunakan uji Chi Square.

\section{Hasil}

\section{Karakteristik Responden}

\section{Jenis Kelamin}

Distribusi responden berdasarkan jenis kelamin dari 67 responden tertinggi $54(80,6 \%)$ berjenis kelamin perempuan dan $13(19,4 \%)$ terendah berjenis kelamin laki-laki (tabel 1 ).

\section{Pendidikan}

Karakteristik responden berdasarkan distribusi pendidikan yang tertinggi yaitu D3 sebanyak 57 responden $(85,1 \%)$, sedangkan responden yang terendah yaitu S1 sebanyak 2 responden $(3,0 \%)$ (tabel 2).

\section{Umur Responden}

Distribusi responden berdasarkan umur dari 67 responden tertinggi 33 orang $(49,2 \%)$ berusia $21-30$ tahun, dan terendah 13 orang $(19,4 \%)$ berusia 41 60 tahun (tabel 3 ). 
Masa Kerja

Karakteristik responden berdasarkan masa kerja dari 67 responden yaitu tertinggi 46 orang $(68,7 \%)>3$ tahun dan terendah 21 orang $(31,3 \%)<$ 3 tahun (tabel 4 ).

\section{Analisa Univariat}

\section{Beban Kerja}

Berdasarkan tabel 5, diketahui responden yang memiliki beban kerja tertinggi pada beban kerja kategori ringan 40 orang $(59,7 \%)$ dan terendah beban kerja kategori berat 27 orang $(40,3 \%)$.

\section{Stres Kerja}

Berdasarkan tabel 6 , diketahui responden yang memiliki stres kerja tertinggi pada stres kerja kategori tinggi 39 orang $(58,2 \%)$ dan terendah stres kerja kategori rendah 28 orang $(41,8 \%)$.

\section{Analisa Bivariat}

Berdasarkan tabel 7, menunjukkan bahwa hasil tabulasi silang antara beban kerja perawat pelaksana dengan stres kerja di RSUD Sleman yaitu yang mengalami beban kerja berat dan stres kerja tinggi sebanyak 24 orang $(35,8 \%)$, sedangkan yang

Tabel 5 | Distribusi frekuensi responden berdasarkan Beban Kerja di RSUD Sleman

\begin{tabular}{rccc} 
No. & Beban Kerja & Frekuensi (n) & Persentase (\%) \\
\hline 1 & Berat & 27 & 40,3 \\
2 & Ringan & 40 & 59,7 \\
\hline & Total & 67 & 100,0
\end{tabular}

Sumber: Data Primer

Tabel 6 | Distribusi frekuensi responden berdasarkan Stres Kerja di RSUD Sleman

\begin{tabular}{rccc} 
No. & Stres Kerja & Frekuensi (n) & Persentase (\%) \\
\hline 1 & Tinggi & 39 & 58,2 \\
2 & Rendah & 28 & 41,8 \\
\hline & Total & 67 & 100,0
\end{tabular}

Sumber: Data Primer

Tabel 7 | Hubungan Beban Kerja perawat pelaksana dengan Stres Kerja di bangsal rawat inap RSUD Sleman

\begin{tabular}{|c|c|c|c|c|c|c|c|}
\hline \multirow{3}{*}{ Beban Kerja } & \multicolumn{4}{|c|}{ Stres Kerja } & \multirow{2}{*}{\multicolumn{2}{|c|}{ Total }} & \multirow{3}{*}{$\rho$-value } \\
\hline & \multicolumn{2}{|c|}{ Tinggi } & \multicolumn{2}{|c|}{ Rendah } & & & \\
\hline & $\mathrm{n}$ & $\%$ & $\mathrm{n}$ & $\%$ & $\mathrm{~N}$ & $\%$ & \\
\hline Berat & 24 & 35,8 & 3 & 4,5 & 27 & 40,3 & \multirow{3}{*}{0,000} \\
\hline Ringan & 15 & 22,4 & 25 & 37,3 & 40 & 59,7 & \\
\hline Total & 39 & 58,2 & 28 & 41,8 & 67 & 100,0 & \\
\hline
\end{tabular}

Sumber: Data Primer mengalami beban kerja berat dan stres kerja rendah sebanyak 15 orang $(22,4 \%)$. Responden yang mengalami beban kerja ringan dan stres kerja tinggi sebanyak 3 orang $(4,5 \%)$ sedangkan beban kerja ringan dengan stres kerja kategori rendah sebanyak 25 orang $(37,3 \%)$.

Berdasarkan hasil uji Chi-Square diperoleh $\rho$ value $=0,000<\alpha 0,05$ maka Ho diterima, yang berarti ada hubungan yang bermakna antara beban kerja perawat pelaksana dengan stres kerja di bangsal rawat inap RSUD Sleman.

\section{Pembahasan}

\section{Beban kerja pada perawat pelaksana di bangsal rawat inap RSUD Sleman.}

Hasil analisis diketahui bahwa beban kerja perawat pelaksana di bangsal rawat inap RSUD Sleman sebagian besar masuk dalam kategori ringan, yaitu sebesar (59,7\%). Hal ini disebabkan karena adanya keseimbangan antara jumlah perawat dengan jumlah pasien dan adanya dukungan dari tenaga non medis seperti staf administrasi yang membantu dalam mengurus arsip rumah sakit, cleaning service membersihkan ruangan dan membuang sampah habis pakai dan juga sebagian besar pasien tergolong dalam minimal care/self care yaitu pasien yang dapat melakukan sendiri kebersihan diri, mandi dan ganti pakaian, makan dan minum atau di bantu dengan kerabat atau keluarga pasien.

Beban kerja adalah sekumpulan atau sejumlah kegiatan yang harus diselesaikan oleh suatu unit organisasi atau pemegang jabatan dalam jangka waktu tertentu.

Hasil penelitian ini tidak sejalan dengan Haryanti (2013) ${ }^{8}$ menunjukkan bahwa berdasarkan persentase beban kerja didapatkan beban kerja perawat di ruang IGD RSUD Kabupaten Semarang, 
sebagian besar adalah berat yaitu sebanyak 27 responden $(93,1 \%)$, dan beban kerja rendah sebanyak 2 responden $(6,0 \%)$.

Menurut Ambarwati (2013) $)^{9}$ beban kerja di pengaruhi oleh berbagai faktor yang sangat komplek, baik faktor internal maupun faktor eksternal. Yang termasuk beban kerja eksternal adalah tugas yang dilakukan bersifat fisik, organisasi dan lingkungan kerja. Ketiga aspek ini sering disebut stressor. Sedangkan faktor internal beban kerja meliputi faktor somatik dan faktor psikis.

\section{Stres kerja pada perawat pelaksana di bangsal rawat inap RSUD Sleman.}

Hasil analisis diketahui bahwa stres kerja perawat pelaksana di bangsal rawat inap RSUD Sleman sebagian besar masuk dalam kategori tinggi yaitu 39 orang $(58,2 \%)$. Hasil penelitian menunjukkan bahwa stres kerja tinggi yang dialami perawat disebabkan oleh beban kerja berat dan beban kerja ringan. Beban kerja terasa memberatkan karena dipengaruhi juga oleh psikologis perawat yang harus menghadapi kondisi-kondisi tertentu seperti merawat luka basah yang terkadang menimbulkan bau tak sedap. Selain itu, perawat yang memiliki beban kerja berat disebabkan karena tuntutantuntutan yang harus dipenuhi seperti harapan pimpinan rumah sakit terhadap pelayanan yang berkualitas, melaksanakan observasi pasien secara ketat selama jam kerja, setiap saat harus dihadapkan pada pengambilan keputusan yang tepat, dan tuntutan keluarga untuk keselamatan dan kesehatan pasien. Sedangkan beban kerja ringan didapatkan akibat adanya kejenuhan dalam bekerja.

Stres merupakan suatu keadaan dimana seseorang mengalami gangguan emosi karena adanya kondisi yang mempengaruhi dirinya yang dapat diperoleh dari dalam maupun dari luar diri seseorang ${ }^{10}$. Stres yang dihadapi oleh perawat dalam bekerja akan sangat mempengaruhi kualitas pelayanan keperawatan yang diberikan kepada pasien. Stres kerja akan berpengaruh pada kondisi fisik, psikologis dan sikap perawat ${ }^{11}$.

Penelitian ini tidak sejalan dengan penelitian yang dilakukan oleh Kusbiantoro $(2008)^{12}$ dengan hasil penelitian menunjukkan bahwa lebih dari sebagian perawat ruang ICU Rumah Sakit
Muhammadiyah Lamongan mengalami stres rendah sebanyak 10 responden $(71,43 \%)$, sebagian mengalami stres kerja sedang sebanyak 3 responden $(21,4 \%)$ dan sebagian kecil mengalami stres kerja berat sebanyak 1 orang $(7,1 \%)$.

\section{Hubungan Beban Kerja Perawat Pelaksana dengan Stres Kerja Di Bangsal Rawat Inap RSUD Sleman}

Berdasarkan hasil uji statistik oleh peneliti dapat disimpulkan bahwa bahwa beban kerja dapat menimbulkan stres kerja pada perawat. Hal ini ditunjukkan oleh hasil statistik dengan uji Chi Square, didapatkan hasil $\rho$ value $(0,000)<\alpha(0,05)$ artinya Ho di tolak atau ada hubungan antara beban kerja perawat pelaksana dengan stres kerja di bangsal rawat inap RSUD Sleman. Hasil penelitian mengenai hubungan antara beban kerja dengan stres kerja menunjukkan bahwa responden yang mengalami beban kerja kategori ringan dan stres kerja kategori rendah sebanyak (37,3\%). Hal ini diartikan bahwa beban kerja ringan berhubungan positif dengan stres kerja rendah. Beban kerja menjadi ringan karena adanya keseimbangan antara perawat dan pasien di bangsal rawat inap serta pasien sudah sebagian tergolong pasien yang mandiri karena bisa melakukan beberapa kegiatan sendiri seperti bergerak, mandi, makan dan minum atau di bantu oleh keluarga sehingga sebagian tugas perawat berkurang dan beban kerja menjadi ringan juga karena faktor lain seperti perawat tahu cara menyelesaikan pekerjaan dengan baik dan memahami dengan jelas terhadap tugas dan tanggung jawab pekerjaannya sehingga perawat tidak mengabaikan tugas-tugasnya juga tidak tertekan dengan tuntutan-tuntutan pekerjaan dan organisasi serta waktu pekerjan yang kadang tidak realistis.

Hasil tabulasi silang menunjukkan bahwa responden tertinggi dalam kategori ringan dengan stres kerja rendah yaitu $(37,3 \%)$ karena beberapa faktor, salah satunya faktor fisiologis dimana seseorang dapat digambarkan dengan pertumbuhan umur, peningkatan umur diharapkan terjadi pertambahan kemampuan motorik sesuai tumbuh kembangnya. Berdasarkan tingkat pendidikan sebagian besar $(81,1 \%)$ perawat berpendidikan D3. Berdasarkan masa kerja $(68,7 \%)$ responden 
memiliki masa kerja > 3 tahun. Masa kerja biasanya dikaitkan dengan waktu mulai bekerja, dimana pengalaman kerja juga ikut menentukan kinerja seseorang. Semakin lama masa kerja, kecakapan dalam menangani pasien akan lebih baik karena mudah menyesuaikan diri dengan pekerjaan sehingga pekerjaan terasa lebih mudah untuk dikerjakan. Berdasarkan penelitian Prihatini $(2008)^{13}$ setiap ruang rawat inap terdapat perbedaan jenis pasien yang berdampak pada kondisi dan beban kerja yang berbeda. Untuk itu perawat harus mempunyai peran sebagai tenaga medis serba bisa, memiliki inisiatif, berperilaku kreatif, serta memiliki wawasan yang luas dengan motivasi kerja yang keras, cerdas, ikhlas dan kerja berkualitas. Jenis pasien yang dirawat di ruangan rawat inap rumah sakit dapat di pandang sebagai tuntutan terhadap pelayanan kesehatan jika tidak di kelola dengan baik maka akan berakibat terjadinya stres kerja. Setiap orang pernah stres dan akan mengalaminya, akan tetapi kadarnya berbeda-beda serta dalam jangka waktu yang tidak sama ${ }^{14}$.

Penelitian sejalan dengan penelitian yang dilakukan oleh Indah (2011) ${ }^{15}$ di unit rawat inap RSUD Kraton Kabupaten Pekalongan dengan jumlah sampel 81 orang dengan hasil uji analisis uji Pearson Product Moment menunjukkan $\rho$ value $(0,040)<\alpha(0,05)$ hal ini berarti terdapat hubungan antara beban kerja perawat dengan stres kerja perawat RSUD Kraton Kabupaten Pekalongan dengan sifat hubungan positif sedang.

\section{Kesimpulan}

Studi ini menunjukkan bahwa beban kerja di bangsal rawat inap RSUD Sleman sebagian besar dalam kategori ringan yaitu sebanyak 59,7 \% responden. Di sisi lain stres kerja di bangsal rawat inap RSUD Sleman sebagian besar dalam kategori tinggi yaitu sebanyak $58,2 \%$ responden.

Hasil uji Chi Square menunjukkan $\rho$ value $(0,000)<\alpha(0,05)$ yang berarti ada hubungan antara beban kerja perawat pelaksana dengan stres kerja di bangsal rawat inap RSUD Sleman.

\section{Bibliografi}

1. Ilyas. Yaslis, 2004. Perencanaan SDM Rumah Sakit:
Teori, Metoda dan Formula, Depok: Fakultas Kesehatan Masyarakat, Universitas Indonesia

2. Supardi, 2007. Analisa Stres Kerja Pada Kondisi Dan Beban Kerja Perawat Dalam Klasifikasi Pasien Di Ruang Rawat Inap Rumkit TK II Putri Hijau Kesdam I/BB Medan.

3. Munandar, AS. 2008. Psikologi industri dan organisasi, edisi 1, UI Press, Jakarta.

4. Kiswandaru,2010.StresKerja.http;//archive.kaskus.co. id/thread/4437750/0/share-artikel-stres-kerja.

5. Notoatmodjo, S. 2012. Metodologi Penelitian Kesehatan. Jakarta : Rineka Cipta.

6. Manuho, E, 2015. Hubungan Beban Kerja dengan Kinerja Perawat Dalam Pemberian Asuhan Keperawatan Di Instalasi Rawat Inap CI RSUP Prof. DR. R. D. Kandou Manado, Skripsi. Program Studi IImu Keperawatan Fakultas Kedokteran, Universitas Sam Ratulangi.

7. Sumarni, Tri ,dkk. 2014. Hubungan Beban kerja Perawat dengan Stres Kerja perawat di Bangsal Bedah Rumah Sakit Umum Daerah dr. R. Goeteng Tarunadibrata Purbalingga, Skripsi, Sekolah Tinggi Ilmu Kesehatan Harapan Bangsa Purwokerto.

8. Haryanti, 2014. Hubungan antara Beban Kerja dengan Stres Kerja Perawat di Instalasi Gawat Darurat RSUD Kabupaten Semarang. Skripsi. STIKES Ngudi Waluyo, Ungaran.

9. Ambarwati, 2014. Pengaruh Beban Kerja terhadap Stres Perawat IGD Dengan Dukungan Sosial Sebagai Variabel Moderating (Studi Pada RSUP Dr.Kariadi Semarang). Skripsi, Fakultas Ekonomika dan Bisnis, Universitas Dipanegoro, Semarang.

10. Pitaloka, 2010. Pengaruh Kondisi Kerja Dan Beban Kerja Terhadap stres Kerja Perawat Di Rsu Kabanjahe. Kab. Karo : Universitas Sumatera Utara. Dikutip http:/repository.usu.ac.id

11. Syafarida, Zuni 2012. Hubungan Beban Kerja Perawat Pelaksana Per Shift dengan Stres Kerja Di Ruang Rawat Inap Rumah Sakit Umum Daerah DR. Zainoel Abidin Banda Aceh, Skripsi, Fakultas kedokteran, Universitas Syiah Kuala, Banda Aceh.

12. Kusbiantoro, D, 2008. Gambaran tingkat beban kerja dan stres kerja perawat diruang Intensive Care Unit (ICU) Rumah Sakit Muhammadiyah Lamongan mendapatkan hasil penelitian menunjukkan bahwa lebih dari sebagian perawat ruang ICU Rumah Sakit Muhammadiyah Lamongan. Skripsi.

13. Hardjana, A. 2004. Stres Tanpa Distres: Seni Mengolah Stres, Yogyakarta: Penerbit: Kanisius

14. Prihatini, L. D. 2008. Analisa hubungan beban kerja dengan stres kerja perawat di ruang rawat inap RSUD Sidikalang. Tesis. Universitas Sumatera Utara, 


\section{Medan.}

15. Indah, Dwi K, 2011. Hubungan Beban Kerja dengan Stres Kerja Perawat Di Unit Rawat Inap RSUD Kraton Kabupaten Pekalongan. 